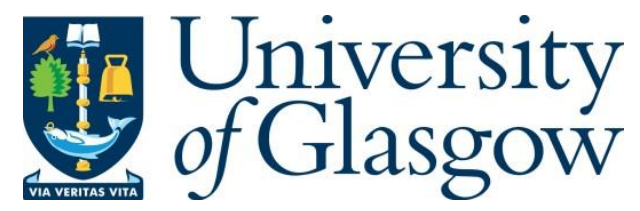

Leifeld, P. and Fisher, D. R. (2017) Membership nominations in international scientific assessments. Nature Climate Change, 7, pp. 730735. (doi:10.1038/nclimate3392)

This is the author's final accepted version.

There may be differences between this version and the published version. You are advised to consult the publisher's version if you wish to cite from it.

http://eprints.gla.ac.uk/145136/

Deposited on: 29 August 2017

Enlighten - Research publications by members of the University of Glasgow http://eprints.gla.ac.uk 
This is a post-print version of the accepted article: Leifeld, Philip and Dana R. Fisher (2017): Membership Nominations in International Scientific Assessments. Nature Climate Change.

\title{
Membership Nominations in International Scientific
}

\author{
Assessments \\ Philip Leifeld* \\ University of Glasgow \\ Dana R. Fisher \\ University of Maryland, College Park
}

\begin{abstract}
International scientific assessments are transnational knowledge-based expert networks with a mandate to advise policymakers. A well-known example is the Millennium Ecosystem Assessment (MA), which synthesized research on ecosystem services between 2001 and 2005, utilizing the knowledge of 1,360 expert members. Little, however, is known about the membership composition and the driving forces behind membership nominations in the MA and similar organizations. Here we introduce a survey dataset on recruitment in the MA and analyze nomination patterns among experts as a complex network. The results indicate that membership recruitment was governed by prior contacts in other transnational elite organizations and a range of other factors related to personal affinity. Network analysis demonstrates how some core individuals were particularly influential in shaping the overall membership composition of the group. These findings add to recently noted concerns about the lack of diversity of views represented in international scientific assessments.
\end{abstract}

\footnotetext{
${ }^{*}$ Corresponding author. Address for correspondence: University of Glasgow, Adam Smith Building, 40 Bute Gardens, Glasgow, G12 8RT, United Kingdom. E-mail: philip.leifeld@glasgow.ac.uk.
} 
Transnational and transgovernmental coordination among states breeds different organizational forms of cooperation, including policy advice through transnational organizations founded by the United Nations [1, 2, 3], such as the Millennium Ecosystem Assessment (MA) or the Intergovernmental Panel on Climate Change (IPCC).

Such international scientific assessments have become increasingly popular as transnational knowledge-based expert networks with a mandate to advise policymakers. It is important to understand their logic and composition, as international cooperation around complex policy topics relies on the credibility and advice of these communities [4]. Yet, the credibility of some of these transnational expert communities has been disputed. Keohane and Nye argue that scientific information is in part socially constructed and that a transnational expert community can only be credible if they produce information through a process that is in accordance with professional norms and characterized by transparency and procedural fairness [5, page 92] (see also [6, 7] for a critical discussion of the social construction of the science of climate change). Despite their many achievements and overwhelmingly positive reputation as facilitators of international cooperation, international scientific assessments are sometimes criticized on the basis of their procedures and composition $[8,9,10]$. Therefore, it is important to understand how scientific assessments recruit new expert members. Taking advantage of innovations in network analysis, here we analyze an original dataset on collaboration and membership nomination patterns between members of the Millennium Ecosystem Assessment, a major environmental assessment that was active between 2001 and 2005 .

Like other scientific assessments, the MA had many members (around 1,300 individual experts), was supported by the United Nations, and was composed of academics and practitioners studying an environmental issue of particular concern: biodiversity and ecosystem degradation. The MA achieved its goal in 2005 when it published its final report [11, 12, 13, 14, 15, 16].

Focusing on one specific community for which data are accessible enables us to assess recruitment processes. Like a recent study on authorship patterns in the Working Group 3 of the IPCC [17], our analysis includes all members of the MA at the time of data collection, not just the scientists. Unlike this analysis by Corbera and colleagues, which focuses on just one 
Working Group in the climate change assessment and authorship patterns, we analyze the nomination process itself, as it determines who actually contributes to the MA as authors.

The most well-known international scientific assessment is the Intergovernmental Panel on Climate Change (IPCC). Although the IPCC has been the focus of studies of its outputs (e.g., [17]), research has yet to study its nominations process. Therefore, this paper studies the MA as a somewhat related international scientific assessment. Although its nominations process was distinct, it followed the IPCC model for recruitment (for a full discussion of similarities and differences, see [13]). In a 2006 commentary in Nature, Loreau and colleagues compare the MA to the IPCC, noting that it provided a much-needed conceptual framework and a synthesis of existing data but criticize the fact that there is currently no mechanism for making this type of assessment global, systematic and sustained [18, page 246]. More recently, Beck and colleagues have compared the successor to the MA - the Intergovernmental Platform on Biodiversity and Ecosystem Services (IPBES), which was formed, in part, as a followup to the MA - to the IPCC [19]. Even in the light of procedural differences, the present dataset provides a unique opportunity to study the formation of an international assessment to understand how the nominations process works in an empirical case.

The MA was launched in 2001 by Secretary General of the United Nations Kofi Annan. Its final report was published in 2005 and was comprised of 68 chapters across three volumes. Like other collaborative scientific networks, some MA members acted as coordinating lead authors (CLA), some as lead authors (LA), and others as contributing authors for individual chapters [20]. Since contributing authors were recruited to participate during the writing process, which was after our data collection period, this study includes data collected from all 361 CLAs and LAs who were active during the research period. According to its mission statement, the Assessment aimed to involve the top scientists from around the world in the evaluation of the state of the science of biodiversity and ecosystem loss.

International scientific assessments have been criticized for being opaque [8], too consensusoriented and hence conservative [21], subject to social construction $[7,6,22,23]$, ineffective at building trust between nations [24], and motivated by self-interest of their members [9, 25]. In 
paraphrasing existing literature, Davis Cross notes that members may just be pursuing their own personal or professional self-interest and raises the important question whether their actions may be simply reflecting their own domestic cultures and strategic interest rather than professional expertise [25]. This reasoning links the aforementioned criticism regarding the outputs produced by an assessment to its composition and the social aspects underpinning its formation.

While we cannot give a definitive answer on the individual motivations of the members of an assessment, we can analyze systematic patterns by which personal networks play a role in the formation of the institution. In line with criticism that has been echoed in the public debate and academic research [26, 27, 28], we argue that personal networks between members of an assessment may take the form of a transnational elite club. In such an arrangement, persons who are members in some international organizations are likely to nominate people they already know from these other activities as new members of the MA. To test whether such transnational elite networks are at work, we test whether an increase in the joint number of shared IO memberships leads (linearly or non-linearly) to an increase in the probability of one person nominating the other person ("Institutional co-memberships" and "Institutional co-memberships (squared)").

We posit that members nominate potential other members through interpersonal linkages formed through previous work-related contacts, i. e., persons they have met while being joint members in other international organizations, like the United Nations Educational, Scientific and Cultural Organization (UNESCO), the International Human Dimensions Programme on Global Environmental Change (IHDP), the UN Development Programme (UNDP), the World Bank, or the IPCC, thereby shaping a transnational "elite club" of "technocrats" [29, 30, 31], i. e., individuals who transcend multiple IOs that are not readily accessible to the majority of actors and who are non-partisan and were not elected [32]. We hypothesize that the probability of member A nominating expert B as a new member is related to the extent of their shared memberships in other international organizations. 


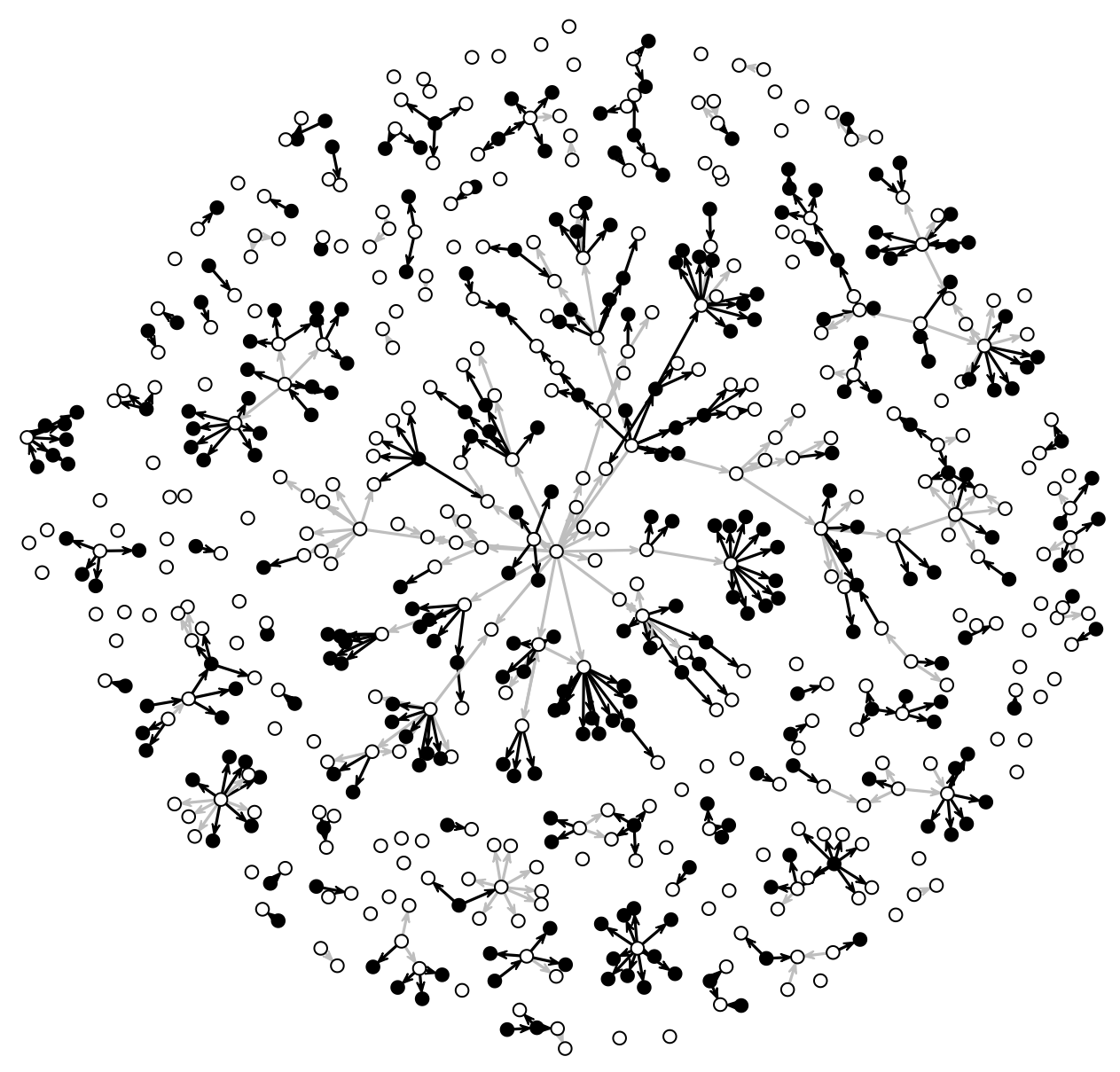

Figure 1: Full network. Respondents are shown as white nodes, non-respondents (including former and future LAs and CLAs) as black nodes, and membership nominations as ties, with nominations among two respondents highlighted in gray.

The selective social nature of such nominations does not strictly imply, however, that elite club nominations lead to unfavorable outcomes. As a matter of practicality, it is possible that they may serve to reduce search costs and may be efficient at identifying competent and willing new members.

\section{Nomination network structure}

Figures 1 and 2 reveal the hierarchical nature of the nomination network: a few central nodesthe founders of the MA - nominated a relatively large number of nodes. These nodes, in turn, nominated further participants, and so forth, leading to a hierarchical tree-like structure 


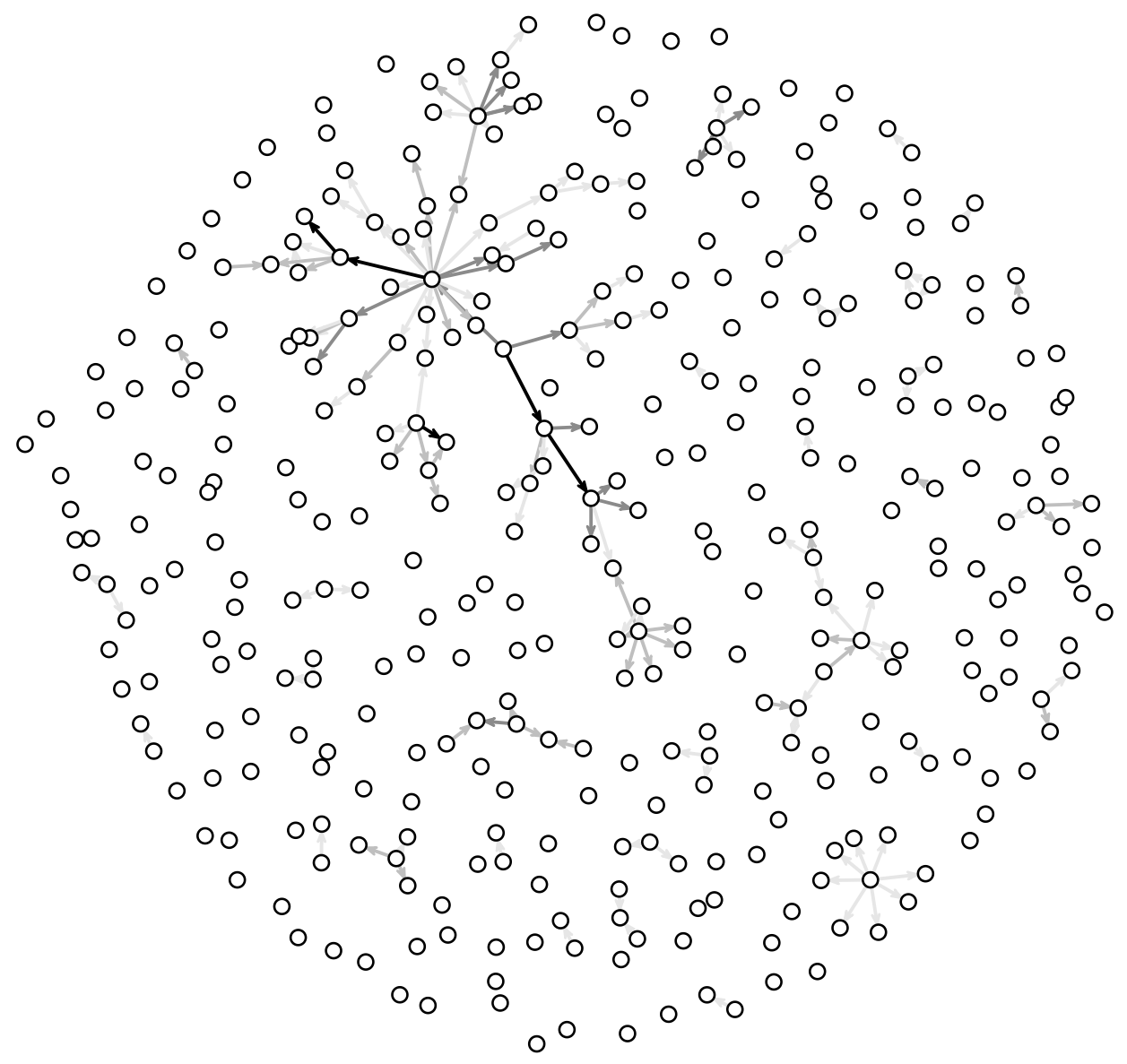

Figure 2: Nomination network among the 361 respondents (including isolates). Ties associated with one shared institutional membership highlighted in medium gray, those with two shared memberships highlighted in dark gray, and those with three or more memberships in black; membership nominations without external co-memberships are denoted as very light gray lines.

similar to snowball sampling, where the origin nodes dominate the remaining nodes in terms of reachability. There are small deviations from a tree structure because some transitive triads (ties $i j, j k$, and $i k$ are present in a triad) can be found in the network, incorporating a small degree of redundancy in the nomination network (for a full discussion of transitive triads, see [33]). Cyclical nominations are quite naturally absent.

The structure of this network indicates that agenda-setting power as exerted through influencing the composition of the epistemic community is distributed very unevenly. A few members of a selected in-group of persons are able to determine the composition of the 


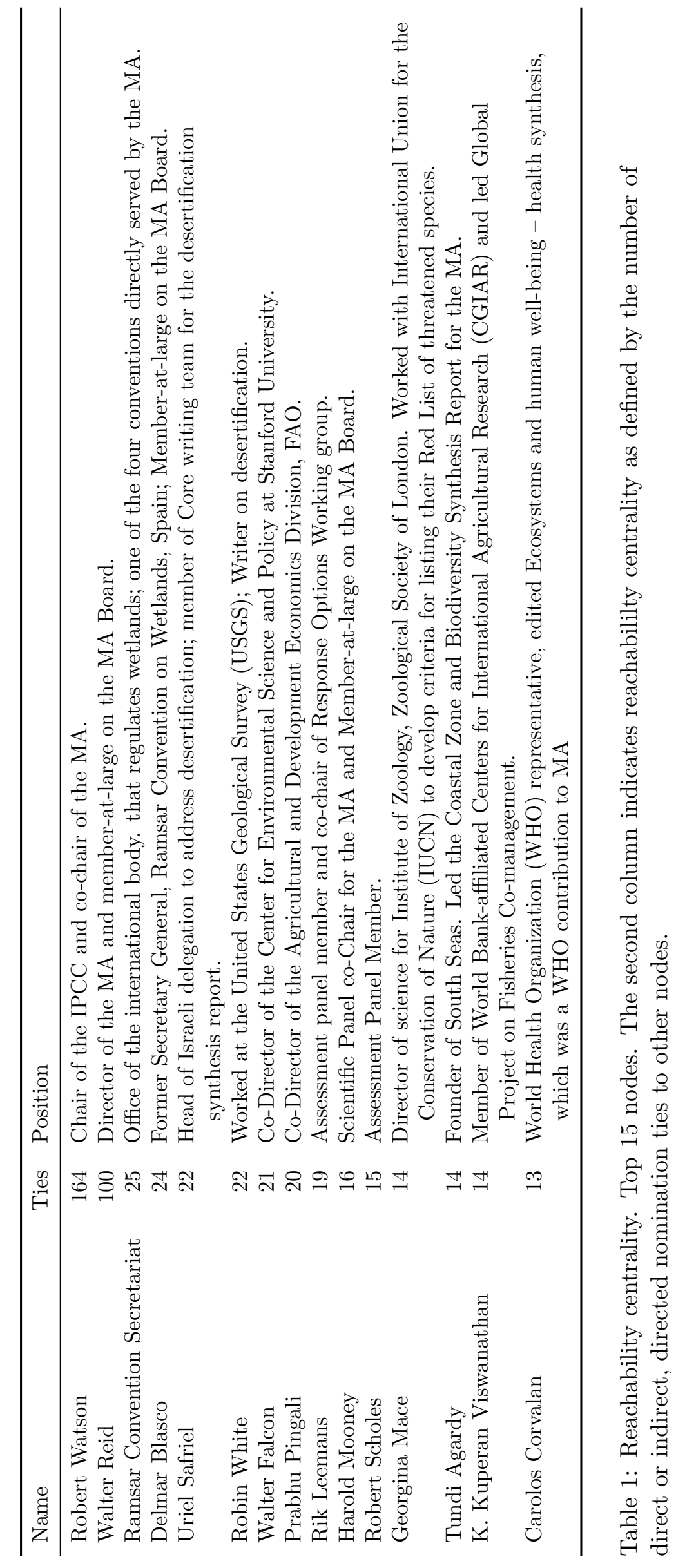


group to a relatively high degree by selecting other members to their liking who can, in turn, nominate new members. Table 1 lists the top 15 nodes in terms of reachability centrality, a custom centrality measure defined in the online methods section, which we consider to be an operationalization of nomination power, along with a description of their role in the MA. Additionally, Supplementary Table 1 lists both the outdegree (i. e., number of nominations) and reachability outdegree for subgroups of leading members of the MA.

A core group of gatekeepers who have diverse interlocking institutional memberships dominate in the MA network. The two most central nodes are Robert T. Watson $(c=164)$, co-chair of the MA and chair of the IPCC (among other board affiliations), and Walter V. Reid $(c=100)$, director of the MA and member-at-large on the MA Board (among other affiliations), followed by other members with scores of 25, 24, 22 etc. Number 15 in the list receives a score of 13 . Although the director has more outgoing nomination ties than the co-chair, the co-chair nominated the director and thus receives a higher score. It is worth noting that only three of these leading members are female.

\section{Inferential network model}

Table 2 shows the results of the inferential network model. The first group of model terms contains the main findings related to Hypothesis 1. Figure 3 shows a visualization of institutional affiliations of MA members, the main independent variable. Controlling for the sender and receiver main effects, "institutional co-memberships" have a strong, significant, positive effect on membership nomination. One additional shared affiliation in an international body increases the chance of being connected by a nomination tie by about 306 percent $(100 \cdot(\exp (1.40)-1)=305.52)$. We also include the squared number of institutional comemberships to account for non-linear effects. The negative coefficient of this squared term indicates a concave effect that levels off with several shared affiliations. In other words, going from one to two shared affiliations has a stronger marginal effect than, say, going from four to five shared organizations. Substantively, the strong institutional co-membership effect demonstrates that personal ties to colleagues from other elite organizations is at least as im- 


\begin{tabular}{lc}
\hline & ERGM \\
\hline Institutional elite memberships & \\
Institutional memberships (receiver) & $-0.11(0.05)^{*}$ \\
Institutional memberships (sender) & $-0.06(0.02)^{* *}$ \\
Institutional co-memberships & $1.40(0.23)^{* * *}$ \\
Institutional co-memberships ${ }^{2}$ & $-0.17(0.05)^{* * *}$ \\
Exogenous controls & \\
Same nationality & $1.68(0.19)^{* * *}$ \\
Same employer/university affiliation & $3.18(0.42)^{* * *}$ \\
Sender male & $0.54(0.29)$ \\
Receiver male & $0.20(0.38)$ \\
Sender male, receiver male & $-0.49(0.40)$ \\
Same area of expertise & $0.61(0.22)^{* *}$ \\
Joint chapter(s) in the report & $3.51(0.19)^{* * *}$ \\
Same type and level of degree & $-0.38(0.19)^{*}$ \\
Receiver has a PhD or MD & $-0.05(0.23)$ \\
Sender has a PhD or MD & $0.25(0.17)$ \\
Receiver is a social scientist & $0.21(0.23)$ \\
Sender is a social scientist & $0.18(0.14)$ \\
Both are social/natural scientists & $0.13(0.19)$ \\
Sender is a CLA & $0.93(0.19)^{* * *}$ \\
Sender CLA $\times$ Institutional co-memberships & $-0.14(0.21)$ \\
Sender is a Leader & $0.62(0.22)^{* *}$ \\
Leader $\times$ Institutional co-memberships & $-0.05(0.19)$ \\
Endogenous dependencies & \\
Edges & $-8.00(0.57)^{* * *}$ \\
Two-stars (incoming) & $-1.44(0.34)^{* * *}$ \\
Two-stars (outgoing) & $0.45(0.07)^{* * *}$ \\
Three-stars (outgoing) & $-0.04(0.01)^{* * *}$ \\
Two-paths & $-0.26(0.10)^{* *}$ \\
Isolates & $0.27(0.29)$ \\
\hline & \\
\hline &
\end{tabular}

${ }^{* * *} p<0.001,{ }^{* *} p<0.01,{ }^{*} p<0.05$

Table 2: Results of the exponential random graph model

portant a factor in shaping the composition of the epistemic community as factors related to subject, expertise, and collaboration. Figure 4 supports this claim by demonstrating that the omission of institutional memberships in the model noticeably hampers predictive dyadic fit.

The second group of model terms considers control variables. While we are primarily interested in the effect of joint memberships in international organizations on the nomination of new members, we treat other subject-related and personal factors as control variables. 


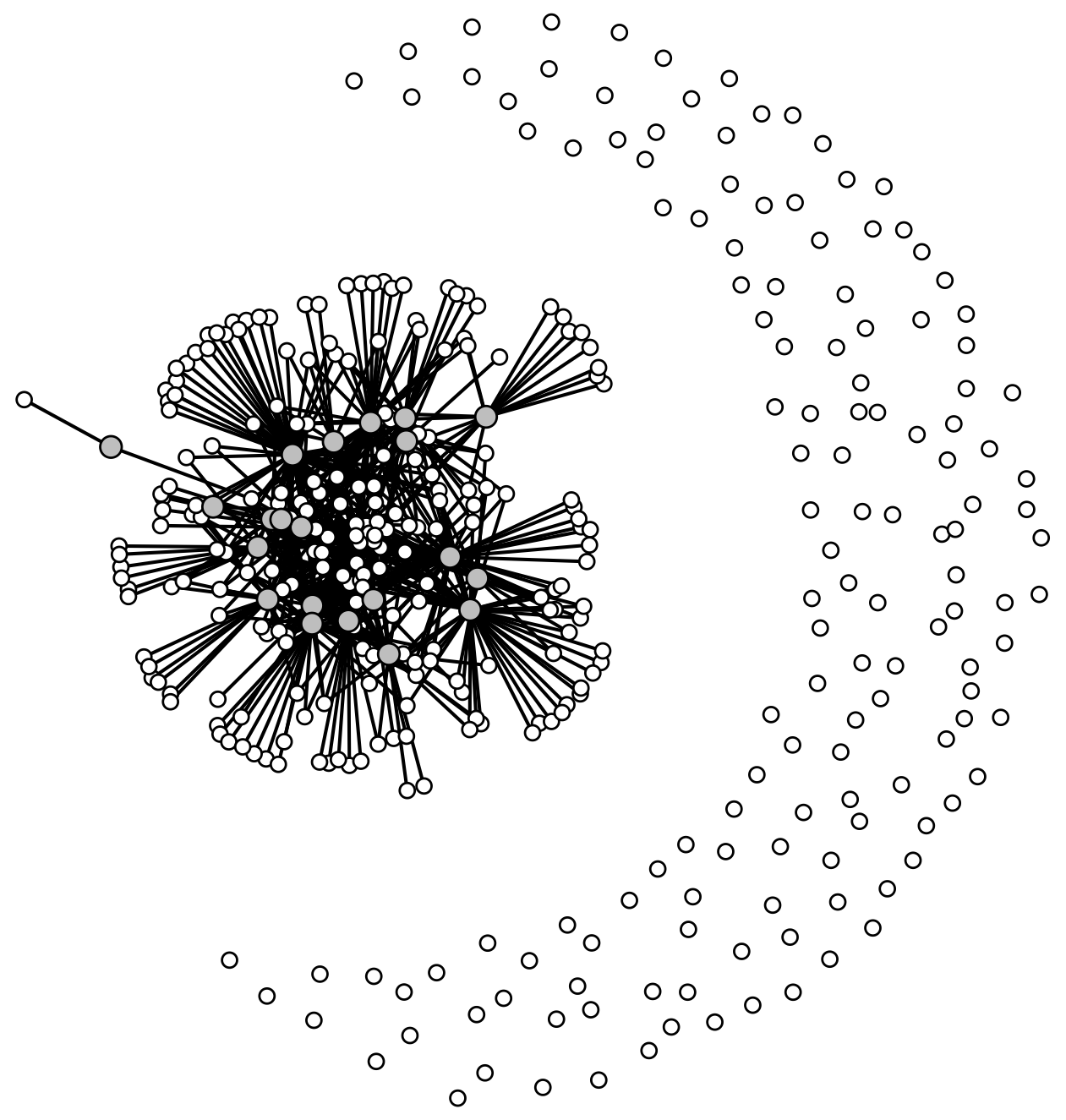

Figure 3: Memberships of the 361 respondents as white nodes; 21 international organizations as gray nodes; membership ties shown as black lines.

We control for whether any two experts are active in the same subject area, such as marine biology, hydrology, or economics ("Same area of expertise") because we expect members to nominate others in order to collaborate on shared subject interests. We also control for actual collaboration in the final assessment report ("Joint chapter(s) in the report") as a stricter (though potentially endogenous) test. As collaboration often takes place between persons of dissimilar ranks, we check for homophily in terms of degree type and level ("Same type and level of degree"). We also expect the leadership of the MA will play a role in nominations. The variable "Sender is a Leader" includes all members who served as the Director, an editor 


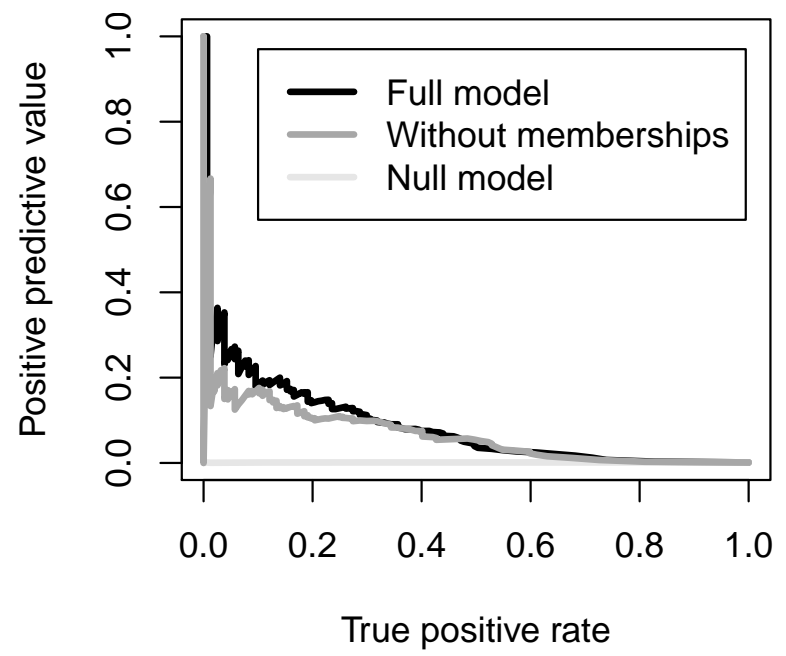

Figure 4: Precision-recall curves for the full model, a model without (shared) memberships in international organizations, and a random graph with the same density.

of a working group, or on the Assessment Panel. Since the coordinating lead authors (CLAs) were seen as leaders of the individual chapters of the assessment, we expect "Sender is a CLA" to play a role in nominations. Using interaction terms, we investigate whether these leadership roles are consequential for the main hypothesis on elite club nominations. We also anticipate that experts with a scientific degree may be more interested and experienced collaboration partners and, therefore, more likely to be nominated ("Receiver has a $\mathrm{PhD}$ or MD"), but also more likely to nominate others because they have a more comprehensive overview of the field ("Sender has a $\mathrm{PhD}$ or $\mathrm{MD}$ "). We control whether the sender or the receiver is a social scientist in order to account for possible differentials in collaboration activity between the two groups ("Receiver is a social scientist" and "Sender is a social scientist," respectively). In terms of additional personal factors in the nomination process, we control for "Same nationality" because we expect that personal networks operate most visibly through embeddedness in relevant networks "at home," and "Same employer/university affiliation" because we expect members to draw on their work- and education-related networks when they bring in potential collaborators. Finally, several model terms control whether nominations follow gender dynamics and take the shape of an "old boys' club" where male members tend to nominate other male persons. 
Among the control variables, particularly having the same nationality and/or the same employer or university affiliation are significant predictors of membership nomination ties. Person $i$ is approximately five times as likely $(\exp (1.68)=5.37)$ to nominate person $j$ if that person has the same nationality compared to those members who have a different nationality. If $j$ has the same employer or university affiliation, this increases the odds of nominating $j$ by about 2,300 percent compared to persons with a different employer/nationality. One interpretation may be that $i$ nominates $j$ because of visibility; i. e., $i$ wants to bring in $j$ because personal favors may pay off in the long run. However, this explanation is not the only plausible interpretation as nominations of persons from the same university of employer may well have subject-related reasons. Persons may have self-selected into the same institute or employer because they are pursuing similar research interests, which would be a legitimate criterion for collaborating with somebody else. Similarly, it may be the case that persons come to appreciate the collaboration with their colleagues and want to extend this fruitful partnership in the MA, which is a similarly legitimate criterion. Future research may shed light on the causal chain and invidual motivations for these patterns.

Neither the variables that represent gender nor the field of the scientist (social versus natural scientist) are statistically significant. We do find higher nomination rates for CLAs and MA members with leadership roles. However, the propensity to engage in elite club nomination patterns as per our hypothesis does not differ between these individuals and other members of the MA.

The third group of model terms models endogenous dependencies between the dyadic membership nomination observations. The membership nomination procedure modeled here has very specific endogenous characteristics that need to be mapped to network statistics in order to account for the way nominations are partly contingent on each other. The online methods section contains details on these endogenous controls and an endogenous goodnessof-fit assessment (see also Supplementary Figures 1-3). 


\section{Conclusion}

If the composition and internal structure of an international scientific assessment is structured by elite cliques and personal affinity, there are likely repercussions to the output generated by the expert network. This is likely exacerbated when such nomination mechanisms are coupled with a skewed power distribution due to the existence of initial seeds in a snowball nomination system. Establishing and examining the link between input and output in detail, however, is beyond the scope of this particular study. Moreover, if similar elite-based recruitment is prevalent also in other international organizations, this finding will consequently lead to selfreinforcing recruitment among transnational elites in the international system more broadly and persistence of a hierarchy. Future research should evaluate effects of possible changes to these procedures given the network formation patterns identified here.

An important part of a future research agenda must be a more detailed analysis of interlocking directorates and gatekeeping between transnational expert networks. The present analysis suggests that the mechanisms represented in the Millennium Assessment may span many bodies within and beyond the United Nations system. The extent to which the findings reported here apply to other scientific assessments is yet unclear. But this research is much needed considering the multitude of overlapping institutional memberships. In addition, given the similarity of the nominations process to that of other scientific assessments including the IPCC, these patterns are likely to be a systematic feature of transnational expert regimes.

From an institutional design perspective, it is a daring decision to design such institutions in a centralized, hierarchical way and put all the agenda-setting and composition-setting power into the hands of a few transnational elites, no matter their reputation or scientific credibility. Since the IPCC is currently gearing up for its Sixth Assessment Report, it is

necessary to understand the nominations process for international scientific assessments and how recruitment to these assessments is related to who eventually serves. 


\section{References}

[1] Selin, H. \& Eckley, N. Science, politics, and persistent organic pollutants: The role of scientific assessments in international environmental co-operation. International Environmental Agreements: Politics, Law and Economics 3, 17-42 (2003).

[2] Haas, P. M. Introduction: Epistemic communities and international policy coordination. International Organization 46, 1-35 (1992).

[3] Ostrom, E. Polycentric systems for coping with collective action and global environmental change. Global Environmental Change 20, 550-557 (2010).

[4] Dingwerth, K. \& Pattberg, P. Global governance as a perspective on world politics. Global Governance 12, 185-203 (2006).

[5] Keohane, R. O. \& Nye, J., Joseph S. Power and interdependence in the information age. Foreign Affairs 77, 81-94 (1998).

[6] Demeritt, D. The construction of global warming and the politics of science. Annals of the Association of American Geographers 91, 307-337 (2001).

[7] Allan, B. B. Producing the climate: States, scientists, and the constitution of global governance objects. International Organization 71, 131-162 (2017).

[8] Adler, C. E. \& Hirsch Hadorn, G. The IPCC and treatment of uncertainties: Topics and sources of dissensus. Wiley Interdisciplinary Reviews: Climate Change 5, 663-676 (2014).

[9] Sebenius, J. K. Challenging conventional explanations of international cooperation: Negotiation analysis and the case of epistemic communities. International Organization $\mathbf{4 6}$, 323-365 (1992).

[10] Vähämaa, M. Groups as epistemic communities: Social forces and affect as antecedents to knowledge. Social Epistemology 27, 3-20 (2013). 
[11] Carpenter, S. R. et al. Science for managing ecosystem services: Beyond the Millennium Ecosystem Assessment. Proceedings of the National Academy of Sciences 106, 1305-1312 (2009).

[12] Guerry, A. D. et al. Natural capital and ecosystem services informing decisions: From promise to practice. Proceedings of the National Academy of Sciences 112, 7348-7355 (2015).

[13] Larigauderie, A. \& Mooney, H. A. The Intergovernmental Science-Policy Platform on Biodiversity and Ecosystem Services: Moving a step closer to an IPCC-like mechanism for biodiversity. Current Opinion in Environmental Sustainability 2, 9-14 (2010).

[14] Mooney, H. A., Duraiappah, A. \& Larigauderie, A. Evolution of natural and social science interactions in global change research programs. Proceedings of the National Academy of Sciences 110, 3665-3672 (2013).

[15] Steffen, W. Interdisciplinary research for managing ecosystem services. Proceedings of the National Academy of Sciences 106, 1301-1302 (2009).

[16] Tallis, H., Kareiva, P., Marvier, M. \& Chang, A. An ecosystem services framework to support both practical conservation and economic development. Proceedings of the National Academy of Sciences 105, 9457-9464 (2008).

[17] Corbera, E., Calvet-Mir, L., Hughes, H. \& Paterson, M. Patterns of authorship in the IPCC Working Group III report. Nature Climate Change 6, 94-99 (2016).

[18] Loreau, M. et al. Diversity without representation. Nature 442, 245-246 (2006).

[19] Beck, S. et al. Towards a reflexive turn in the governance of global environmental expertise. the cases of the IPCC and the IPBES. GAIA - Ecological Perspectives for Science and Society 23, 80-87 (2014).

[20] IPCC - Intergovernmental Panel on Climate Change. How does the IPCC work? http: //www.ipcc.ch/organization/organization_structure.shtml, accessed July 1, 2017 (2017). 
[21] Hansen, J. E. Scientific reticence and sea level rise. Environmental Research Letters 2, 024002 (2007).

[22] Hulme, M. \& Mahony, M. Climate change: What do we know about the IPCC? Progress in Physical Geography 34, 705-718 (2010).

[23] Jasanoff, S. States of Knowledge: The Co-production of Science and the Social Order (Routledge, London and New York, 2004).

[24] Mitchell, R. B., Clark, W. C., Cash, D. W. \& Dickson, N. M. Global Environmental Assessments: Information and Influence (MIT Press, Cambridge, MA, 2006).

[25] Davis Cross, M. K. Rethinking epistemic communities twenty years later. Review of International Studies 39, 137-160 (2013).

[26] Stone, D. Global public policy, transnational policy communities, and their networks. Policy Studies Journal 36, 19-38 (2008).

[27] Richardson, I. N., Kakabadse, A. P. \& Kakabadse, N. K. Shaping global political realities: The workings of transnational elite networks. The World Financial Review 32-35 (2012).

[28] Minas, S. The rise of transnational networks in climate change governance: A study in hybridity. Transnational Law Institute Think! Paper 5/2015 (2015).

[29] Keohane, R. O. \& Nye, J., Joseph S. Between centralization and fragmentation: The club model of multilateral cooperation and problems of democratic legitimacy. In Porter, R. B., Sauve, P., Subramanian, A. \& Beviglia Zampetti, A. (eds.) Efficiency, Equity, and Legitimacy: The Multilateral Trading System at the Millennium (Brookings Institution Press, Washington, D.C., 2001).

[30] Slaughter, A.-M. The accountability of government networks. Indiana Journal of Global Legal Studies 8, 347-367 (2001).

[31] Kaiser, K. Transnational relations as a threat to the democratic process. International Organization 25, 706-720 (1971). 
[32] McDonnell, D. \& Valbruzzi, M. Defining and classifying technocrat-led and technocratic governments. European Journal of Political Research 53, 654-671 (2014).

[33] Jasny, L., Waggle, J. \& Fisher, D. R. An empirical examination of echo chambers in US climate policy networks. Nature Climate Change 5, 782-786 (2015). 


\section{Methods}

\section{Survey}

Of the universe of 1,360 persons who were MA members at some point, 739 unique persons were authors of chapters in the final assessment report. Of these, 117 acted as coordinating lead authors (CLA), and 415 of them acted as lead authors (LA), together comprising a set of 493 persons (due to overlapping roles across chapters). In the winter of 2003-2004, 190 of these 493 authors and coordinating lead authors were already members of the MA, and an additional 171 persons with the same designation were present who later dropped out before the report was written. Data were collected during this time period through an online survey (winter 2003-2004). The survey was endorsed by the directorate of the MA, which led to a complete cross-section of nomination data without any unit non-response. We expect that there is a (relatively small) degree of missing data due to recall problems; but ex-post, it is not possible to assess the extent or properties of these missing data. However, all respondents had the same opportunity to provide voluntarily the names of persons they had nominated as members. Missing nomination data were also imputed by asking not only whom a member had nominated but also by whom a member had been nominated, thereby minimizing measurement error. All 361 lead authors (LA) and coordinating lead authors (CLA) that were engaged in the assessment at the time were surveyed. It is worth noting that data collection took place after the Assessment's structure had been finalized while the individual chapters were being outlined and drafted (see http://www.millenniumassessment.org/en/History.html for a complete timeline of the Assessment). Supplementary Figure 4 summarizes the timeline and selection.

The nomination network includes 178 persons (among them, 100 respondents) who nominated at least one other person, and 462 persons who were nominated by respondents (248 of whom were respondents themselves). Overall, the dataset includes a total of 551 nominators or nominees (279 of whom are respondents). Adding these 551 nominators and nominees to our list of 361 lead authors and coordinating lead authors leaves us with 633 unique individuals of potential nominators or nominees who were also members, after duplicates have been 
removed. We employ this "extended" network of 633 persons for our descriptive analyses and visualizations. As covariates are available only for the 361 lead authors and coordinating lead authors (the set of persons with nomination power), and not mere author members or past or prospective (coordinating) lead authors at the point of data collection, we estimate the statistical model on this complete cross-section of 361 lead authors and coordinating lead

authors (i.e., the "core" network of all members with nomination power at the time of data collection, whether exercised or not).

The MA recruited new members through a nomination process. Through its four working groups (Sub-Global, Conditions, Scenarios, and Policy Responses), members of the Assessment, its Board, and other participants were given the opportunity to nominate experts to participate in the Assessment. This process began with multiple nominations from the Director and Board of the Assessment. Although some people involved in the Assessment were self-nominated, these self-nominees had to be approved by the Chair of one of the working groups in order to be invited to participate further in the process. Many of the lowest ranking authors on each chapter - the contributing authors - were nominated by the other authors of the chapter themselves to fill gaps in writing. As such, we do not include the contributing authors in the analysis as they did not exert any influence over the membership composition of the community and many were not nominated to serve until after our period of data collection.

\section{Reachability outdegree as a custom centrality measure}

To operationalize nomination power, we construct a custom centrality measure (detailed results shown in Tables 1 and 2 in the main manuscript). First, we compute the reachability matrix of the directed nomination network. The reachability matrix contains a 1 if row actor $i$ is strongly connected (i. e., has a directed path of arbitrary length) to column actor $j$; otherwise the cell entry in the matrix is 0 . This matrix indicates who predates whom in the network in terms of the nomination chain. Second, we compute outdegree centrality for this reachability matrix, which corresponds to the row sums of the matrix. These outdegree 
centralities of the reachability matrix are a direct operationalization of agenda-setting power. For each actor, the value indicates how many other actors depend directly or indirectly on nominations originating from this focal actor.

Supplementary Table 1 provides summary statistics for the extended network with 633 members. It shows the nomination outdegree and reachability outdegree for several subgroups of leading members.

\section{Network visualizations and ERGM}

We plot the nomination network among all persons mentioned in the dataset (Figure 1 in the main manuscript) and, alternatively, among LA and CLA respondents (Figure 3 in the main manuscript) using standard network layout algorithms [37]. However, only an inferential network model can control for subject-related and personal factors and properly account for network dependence in the data-generating process. To infer the generative properties of the nomination network, we employ an exponential random graph model (ERGM) (Table 2 in the main manuscript). ERGMs are an extension of logistic regression models that permit modeling of the dependencies among observations on top of exogenous covariates. This process enables us to circumvent the independence assumption of traditional regression models, and at the same time it offers interesting possibilities for theorizing about network phenomena [36], which has been seen as one of the "holy grails of the social sciences" [42, page 245].

The ERGM is estimated by Markov Chain Monte Carlo Maximum Likelihood Estimation (MCMC-MLE). Extensive degeneracy and convergence tests were conducted to ensure that the model fits well (Supplementary Figure 1) and the estimation converges (Supplementary Figures 2 and 3). We used the network package [35] and the sna package [34] for the statistical computing environment $\mathrm{R}$ [41] for descriptive analysis and the ergm package [38] for parameter estimation. For goodness-of-fit assessment, we employed the R package xergm [40], and for reporting the statistical results, we used the texreg package for $\mathrm{R}$ [39].

The edges term acts as an intercept like in a regression model. The two-stars and threestars terms govern the degree distributions of the nodes. An incoming two-star is a local 
network configuration where a node has two incoming ties. The term therefore captures the clustering of incoming edges into popular nodes. The negative two-stars term indicates that fewer two-stars are present than expected by chance, which is a sign of "anti-popularity" of nodes. In other words, there is a tendency to have fewer incoming ties than expected in a random graph because non-members can usually be nominated only once before they become a member. This pattern is evident when looking at the network: most nodes have only one single incoming connection, hence the negative coefficient. A positive outgoing twostars term and a negative outgoing three-stars term jointly represent very skewed outdegree distributions, similar to polynomial terms in a regression framework. This captures the fact that some of the members of the nomination network had an overwhelming influence on the nomination network when the community was founded. We can clearly observe this finding in the nomination network in Figure 1 in the main manuscript, where a few original nominators are responsible for a relatively large fraction of nominations. The negative two-paths term indicates that fewer directed two-paths $(i j k)$ exist than pure chance would predict, given the other model terms. The isolates term accounts for the tendency of many nodes not to be connected to other nodes.

\section{Endogenous model terms}

Membership nominations follow a temporal pattern where somebody who has been nominated cannot be nominated again (with an exception being the reception of two simultaneous nominations). In the topology of the network, this leads to a specific distribution of indegree centrality (controlled by the incoming two-star model term), where most nodes only receive a single nomination tie, and to the absence of redundant paths, meaning that two-paths in the network tend not to be closed by direct ties. A related consequence is that nodes further downward along the nomination chain get to nominate fewer persons on average because the set of eligible experts shrinks as more people have been nominated successfully (outgoing *stars). Together, these endogenous model terms capture the network dependencies of the 
MA nomination network well. This claim is supported by the comparative goodness-of-fit assessment in Supplementary Figure 1.

\section{Endogenous model fit}

Supplementary Figure 1 assesses the endogenous model fit of the model presented in the main document (first and second row) and a model without endogenous dependencies (for comparison with a standard logistic regression model). One thousand networks are simulated from the respective model, and the distributions of endogenous network properties like geodesic distance or shared partners across the simulations (the boxplots in the figures) are plotted against the observed values of the same network statistics (the solid black line). The observed and simulated networks are very much in line for the full model (first and second row) but deviate in the model without endogenous dependencies (third and fourth row). This demonstrates that the additional model complexity of the ERGM is worth the effort.

\section{MCMC diagnostics}

Supplementary Figures 2 and 3 present the MCMC trace and the distribution of parameter

changes along the MCMC chain for each model term. The model shows no signs of degeneracy or convergence problems.

\section{Interpretation of institutional co-membership effect}

The institutional co-membership effect is introduced as a main effect and a squared term to capture a concave functional form. Supplementary Figure 5 shows a marginal effects plot for the Institutional co-memberships. The average effect is positive up to the point of eight shared co-memberships. After that, the effect becomes negative. However, the bar plot shown in Supplementary Figure 6 demonstrates that this is not substantively important as there are very few observations with more than four shared institutional memberships; the maximum number is 13. Supplementary Figure 7 plots the predicted probabilities for the most common groups, i.e., up to four institutional co-memberships, including the 95 percent confidence 
interval around the predictions. After that point, the probability would level off, but there are few observations.

\section{Ethics statement and data availability}

Data were collected in accordance with Columbia University policies on Human Subjects research (Columbia University IRB Protocol \#AAAA2069). Informed consent was obtained from all subjects. The survey instrument, the script used for data analysis, and the log file are archived at the Harvard Dataverse (http://dx.doi.org/10.7910/DVN/TTCTIY).

\section{References}

[34] Carter T. Butts. Social network analysis with sna. Journal of Statistical Software, 24(6):1-51, 2008.

[35] Carter T. Butts. network: A package for managing relational data in R. Journal of Statistical Software, 24(2):1-36, 2008.

[36] Skyler J. Cranmer, Philip Leifeld, Scott D. McClurg, and Meredith Rolfe. Navigating the range of statistical tools for inferential network analysis. American Journal of Political Science, 61(1):237-251, 2017.

[37] Thomas M. J. Fruchterman and Edward M. Reingold. Graph drawing by force-directed placement. Software: Practice and Experience, 21(11):1129-1164, 1991.

[38] David R. Hunter, Mark S. Handcock, Carter T. Butts, Steven M. Goodreau, and Martina Morris. ergm: A package to fit, simulate and diagnose exponential-family models for networks. Journal of Statistical Software, 24(3):1-29, 2008.

[39] Philip Leifeld. texreg: Conversion of statistical model output in R to LaTeX and HTML tables. Journal of Statistical Software, 55(8):1-24, 2013.

[40] Philip Leifeld, Skyler J. Cranmer, and Bruce A. Desmarais. xergm: Extensions of Exponential Random Graph Models, 2017. R package version 1.8.2. 
[41] R Core Team. R: A Language and Environment for Statistical Computing. R Foundation for Statistical Computing, Vienna, Austria, 2015.

[42] Michael D. Ward, Katherine Stovel, and Audrey Sacks. Network analysis and political science. Annual Review of Political Science, 14:245-264, 2011. 


\section{Correspondence}

All correspondence for this paper should be directed to:

Philip Leifeld

University of Glasgow

Adam Smith Building

40 Bute Gardens

Glasgow, G12 8RT

United Kingdom

philip.leifeld@glasgow.ac.uk

\section{Acknowledgements}

This project was funded, in part, by a grant from a 2004 Columbia University Faculty Development Grant and by the Swiss National Science Foundation (IZK0Z1_157912/1). Part of this work was carried out at the Swiss Federal Institute of Aquatic Science and Technology (Eawag) and at the University of Bern, Institute of Political Science. The authors wish the thank Walter V. Reid and the MA Board for granting them access and allowing them to collect the survey data. The authors would also like to thank Paul-Brian McInerney and Erzsebet Fazekas for their research assistance during the early stages of this project.

\section{Author Contributions}

DRF directed research design and data collection. PL was responsible for data analysis. PL and DRF contributed to project design, write-up of findings, and revisions. 


\title{
Supplementary Information
}

Membership Nominations in International Scientific Assessments

\author{
Philip Leifeld Dana R. Fisher
}




\begin{tabular}{lrrrrr}
\hline & & Nomination & Reachability \\
& $\mathrm{N}$ & outdegree & $\mathrm{SD}$ & outdegree & $\mathrm{SD}$ \\
\hline All members & 633 & 0.78 & 1.93 & 2.65 & 8.18 \\
Coordinating Lead Authors & 46 & 2.61 & 3.18 & 4.70 & 4.76 \\
Lead Authors & 197 & 0.72 & 2.14 & 3.20 & 13.73 \\
Director & 1 & 17.00 & 0.00 & 100.00 & 0.00 \\
Assessment Panel & 13 & 3.23 & 3.06 & 20.08 & 43.81 \\
Working Group Editors & 10 & 2.80 & 2.30 & 8.60 & 6.93 \\
\hline
\end{tabular}

Supplementary Table 1: Outdegree and reachability outdegree of leading members 

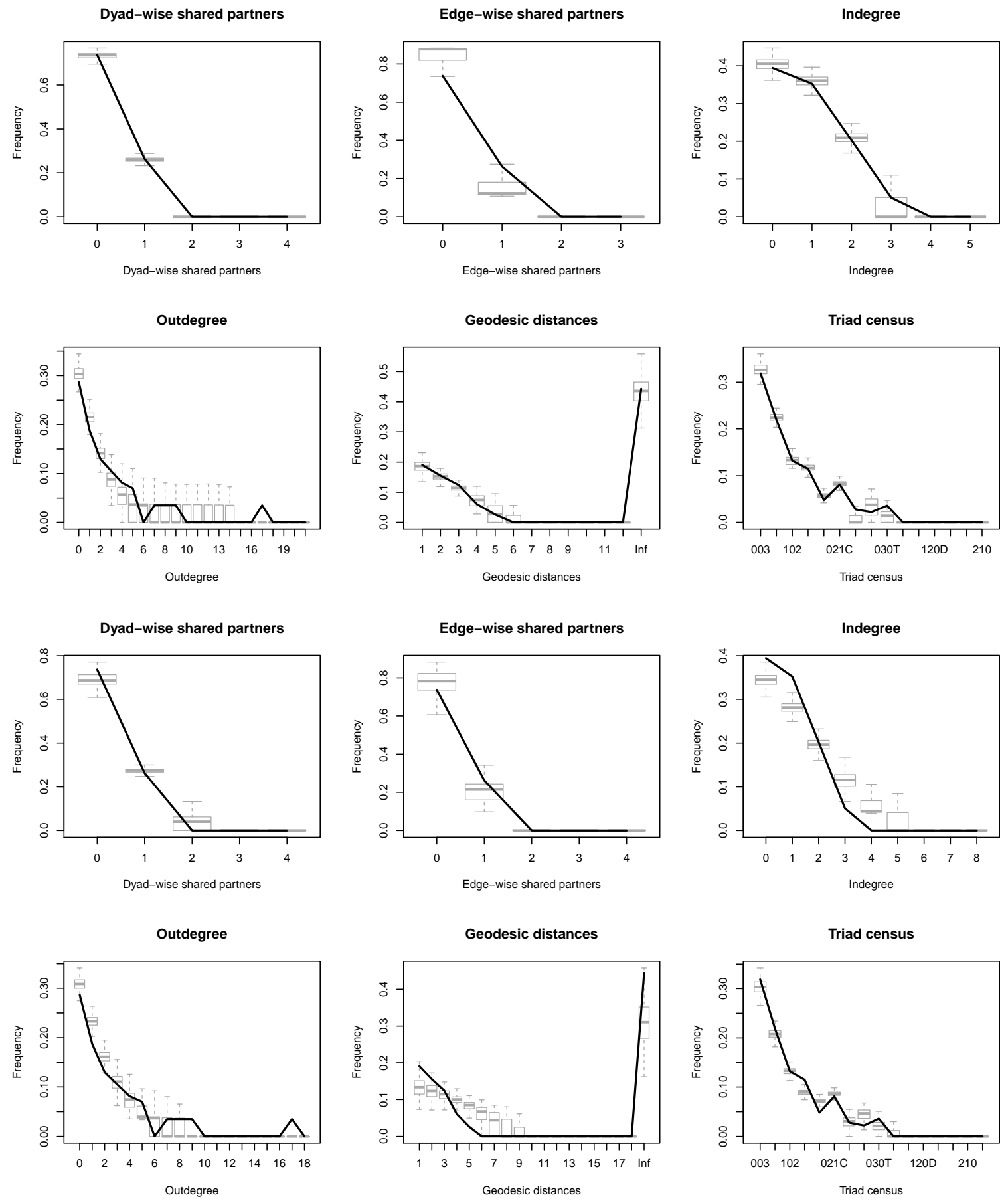

Supplementary Figure 1: Endogenous goodness of fit of the parametric model (first and second row) and the same model without any endogenous network dependency terms (third and fourth row). 1,000 simulated networks based on the model (boxplots) versus the observed network (black line) according to six auxiliary network statistics. Horizontal lines in the boxplots denote the median of a statistic across simulated network, boxes denote upper and lower quartile, and upper and lower wiskers denote maximum and minimum values excluding outliers. The logistic regression model (third and fourth row) fits considerably worse than the ERGM because network dependencies are not modeled. 

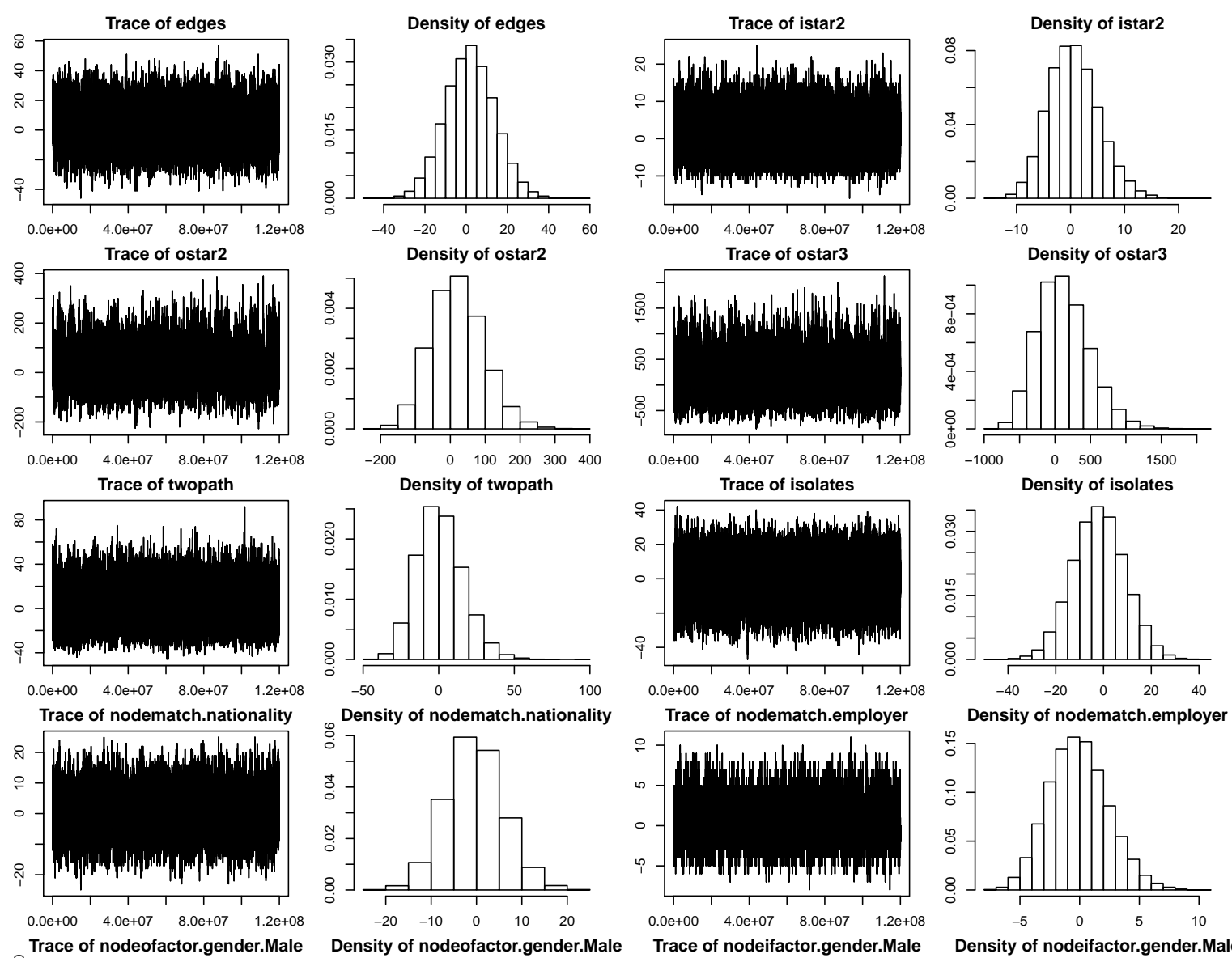

Trace of nodeofactor.gender.Male
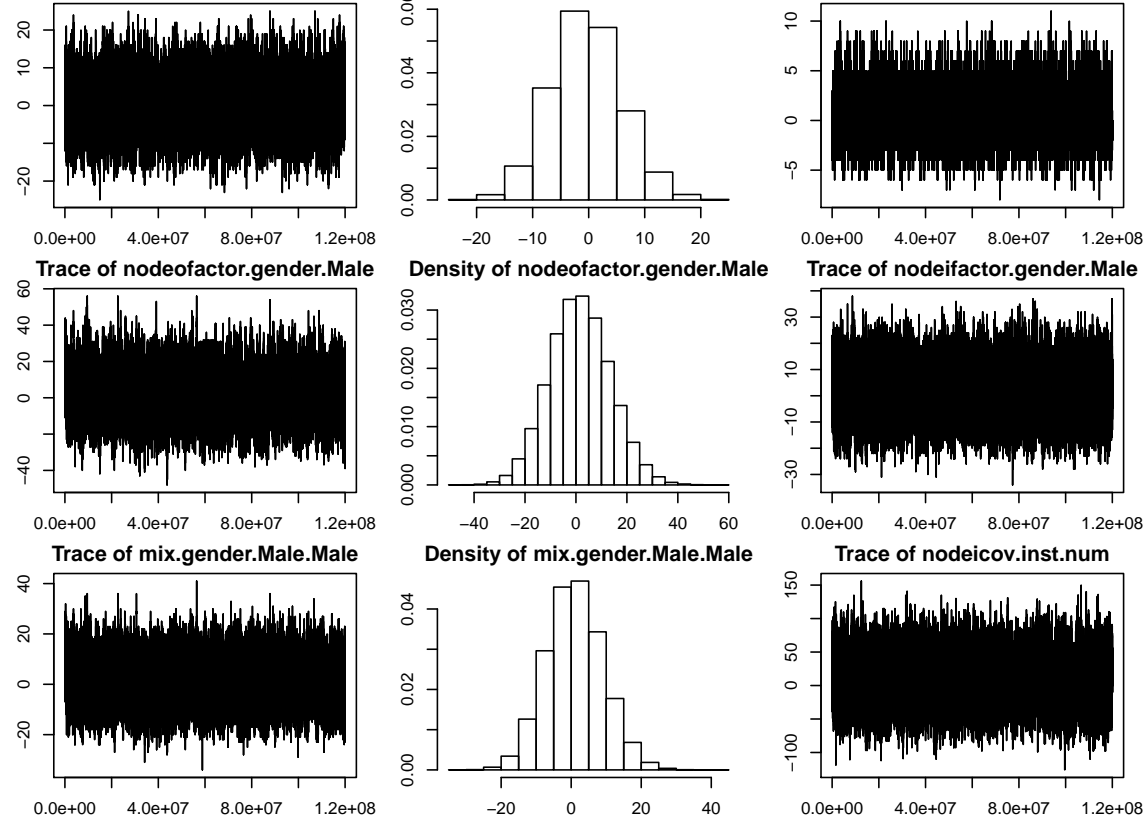

Trace of nodeifactor.gender.Male
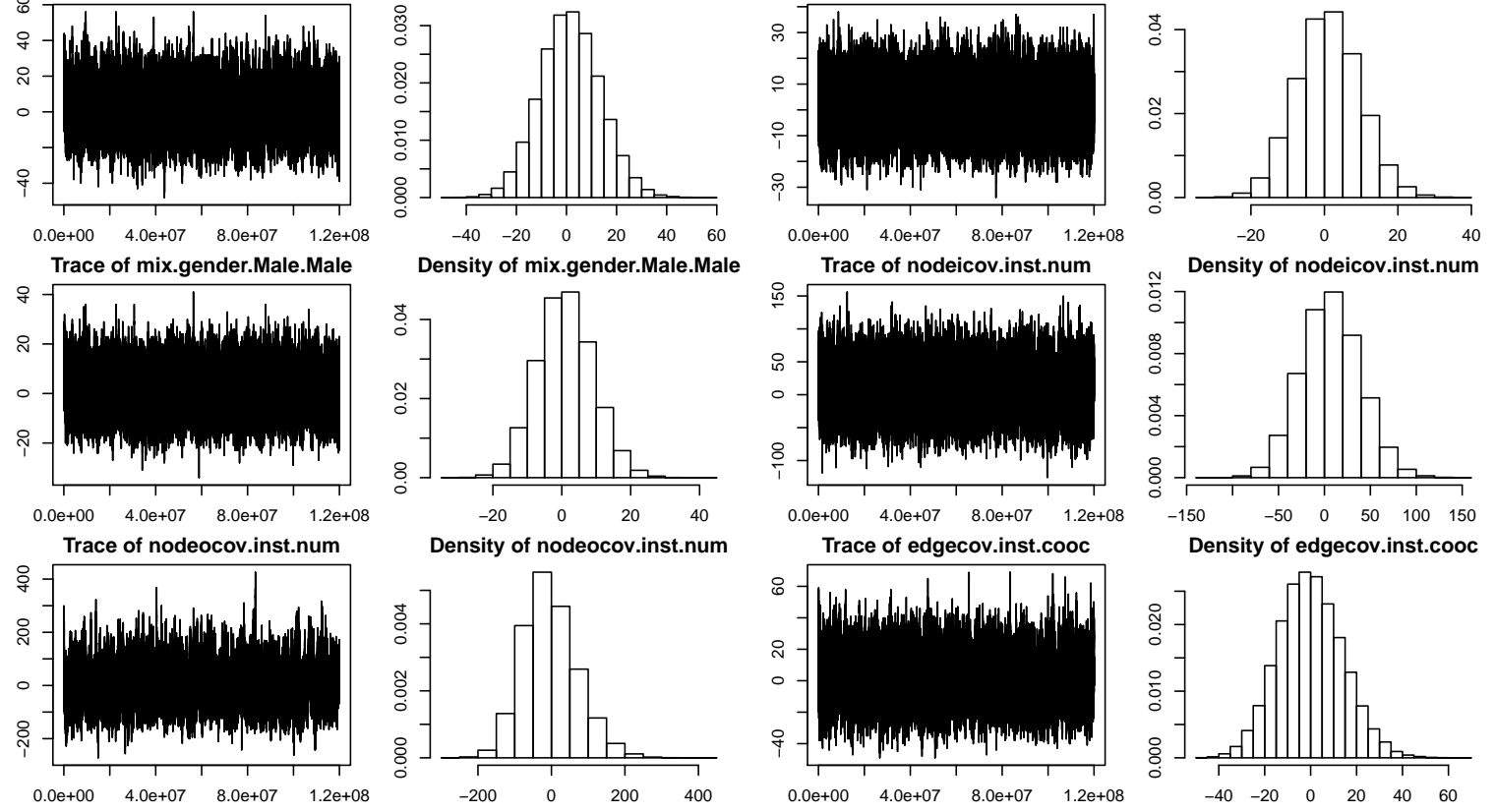

Supplementary Figure 2: MCMC trace and density of parameter changes along the

MCMC chain (part 1). 

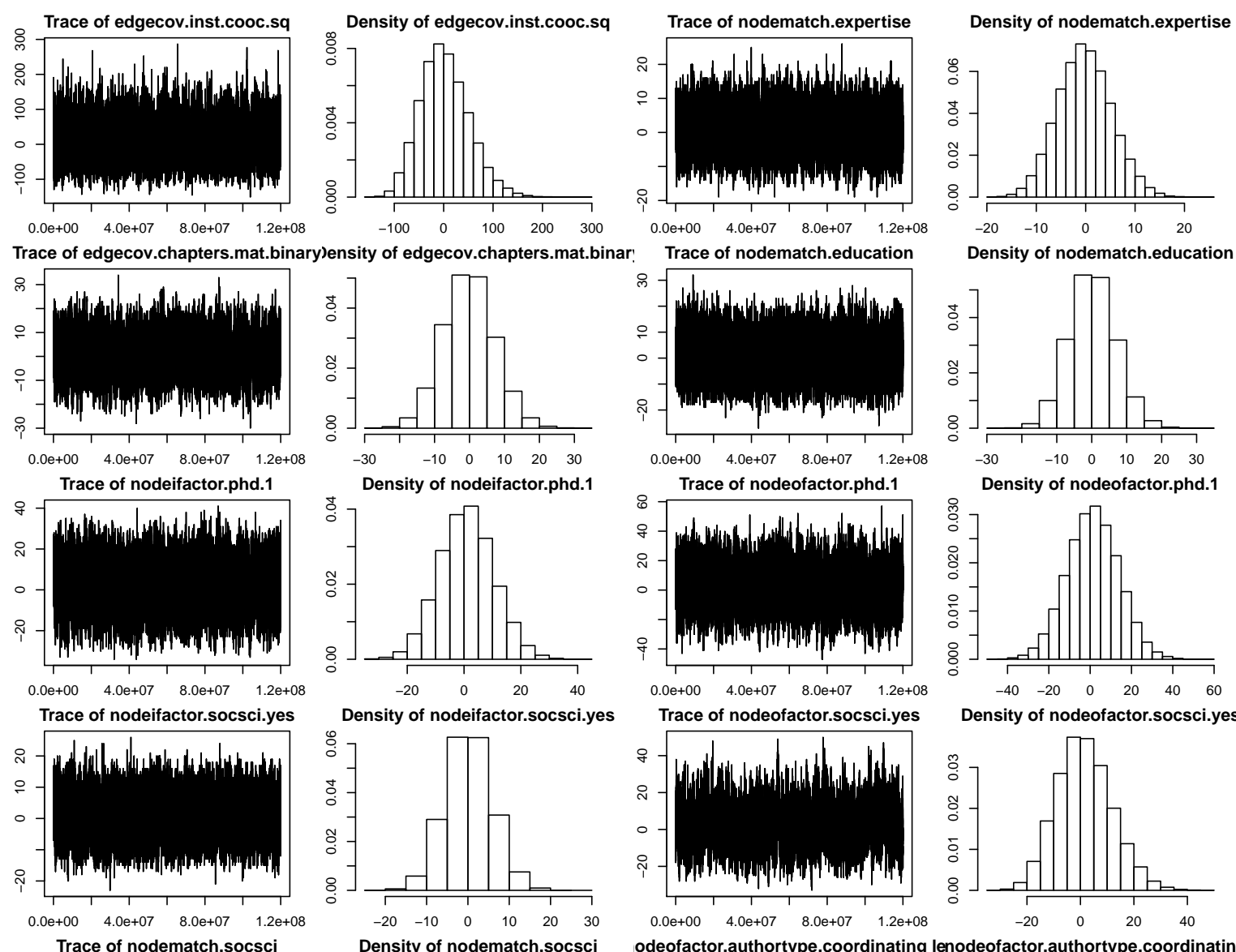

Trace of nodeofactor.socsci.yes
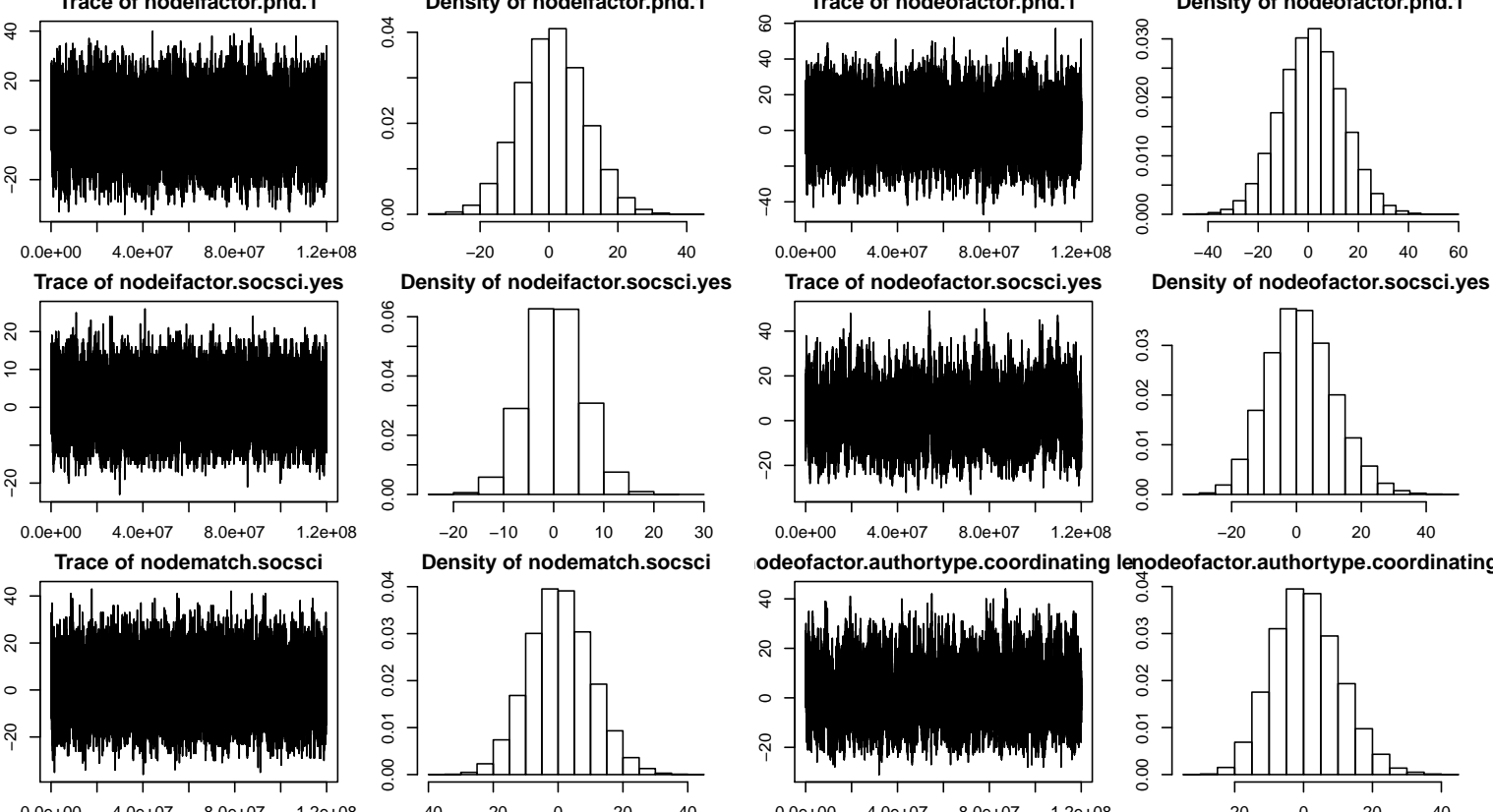

Trace of edgecov.cla.interaction
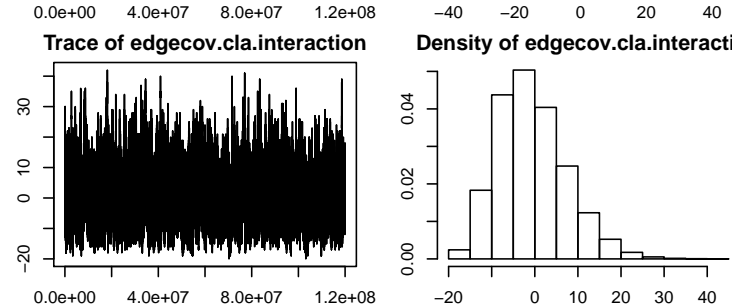

Density of edgecov.cla.interaction

odeofactor.authortype.coordinating lenodeofactor.authortype.coordinating I
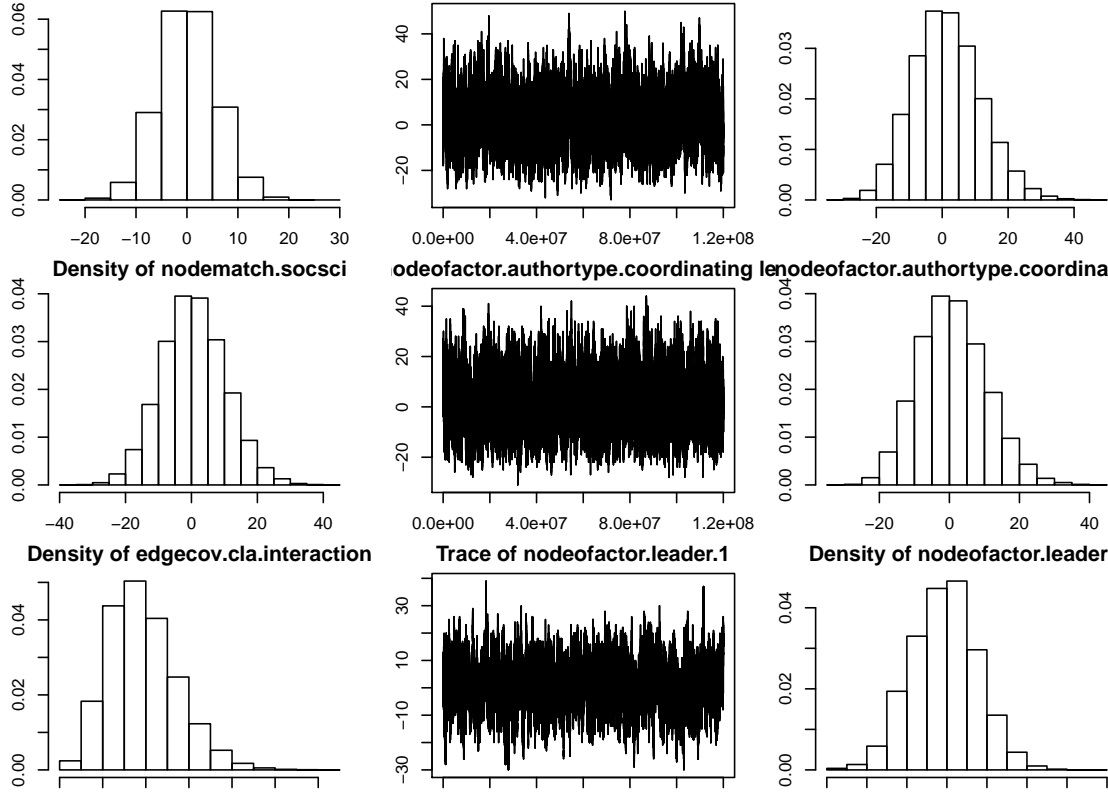

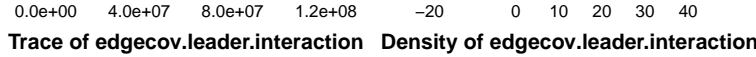

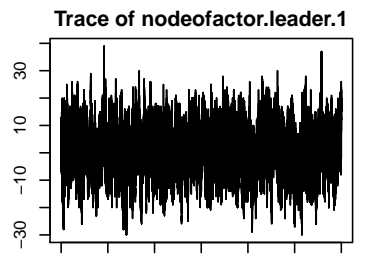

Density of nodeofactor.leader.1
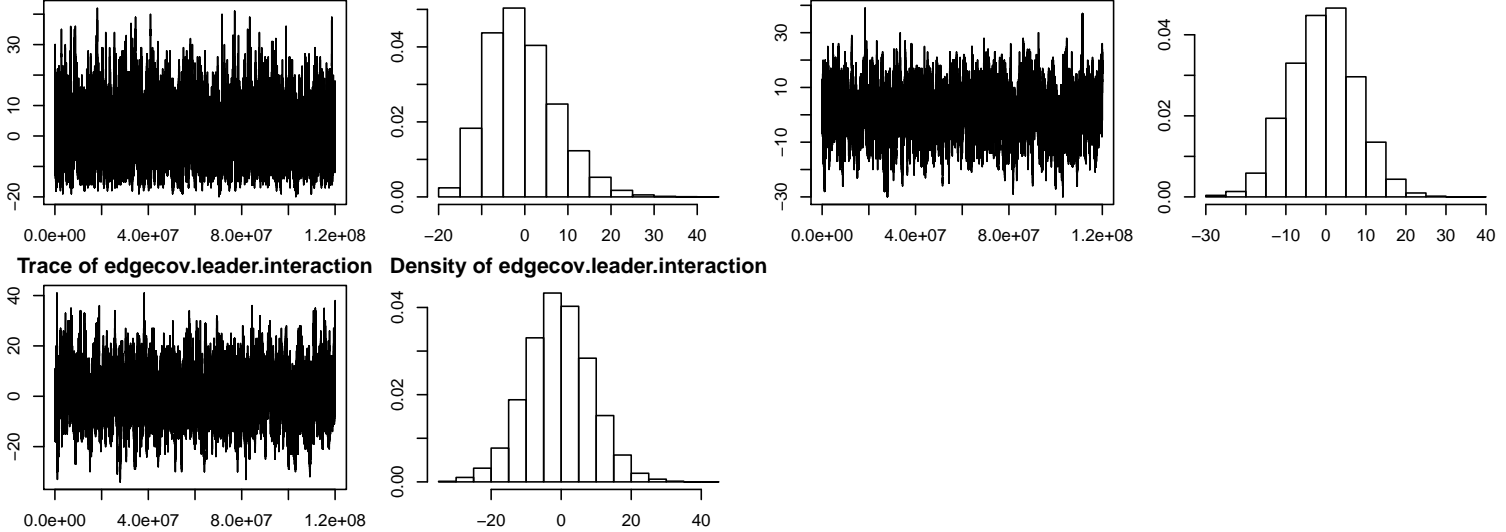

Supplementary Figure 3: MCMC trace and density of parameter changes along the MCMC chain (part 2). 
Survey: 361 members with nomination authority (LA and CLA) Report: 493 authors with nomination authority (LA and CLA)

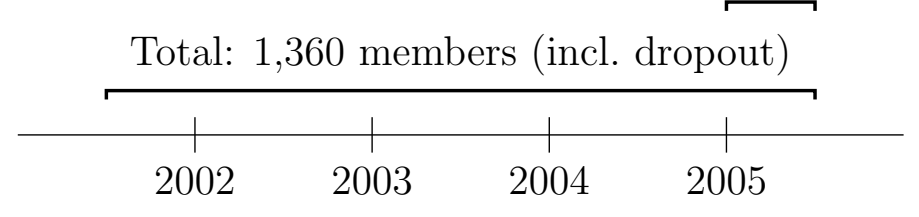

Supplementary Figure 4: Timeline and selection of MA members for the survey. 


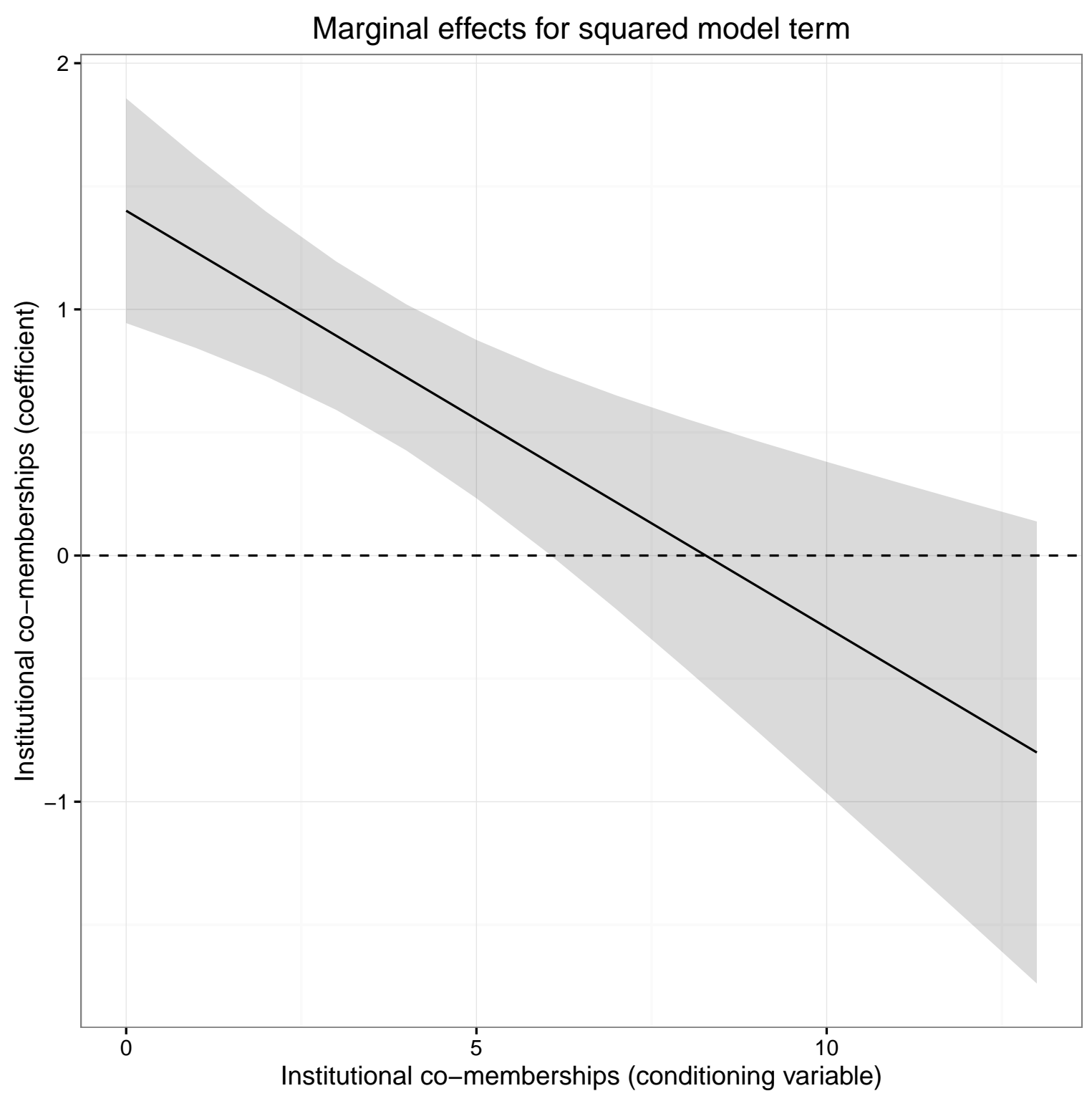

Supplementary Figure 5: Marginal effect plot for Institutional co-memberships. 


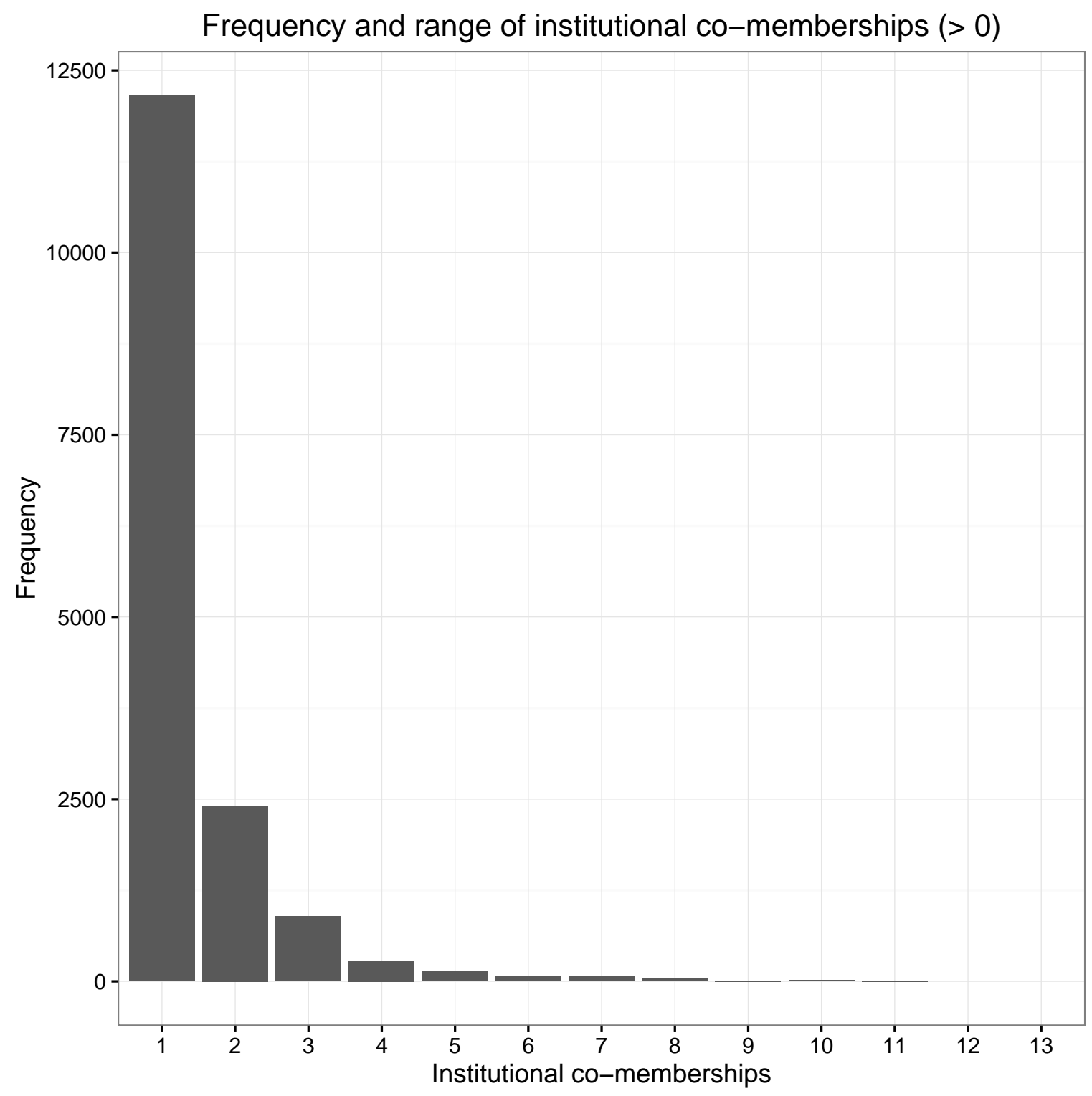

Supplementary Figure 6: Absolute frequencies of dyadic institutional co-memberships. 


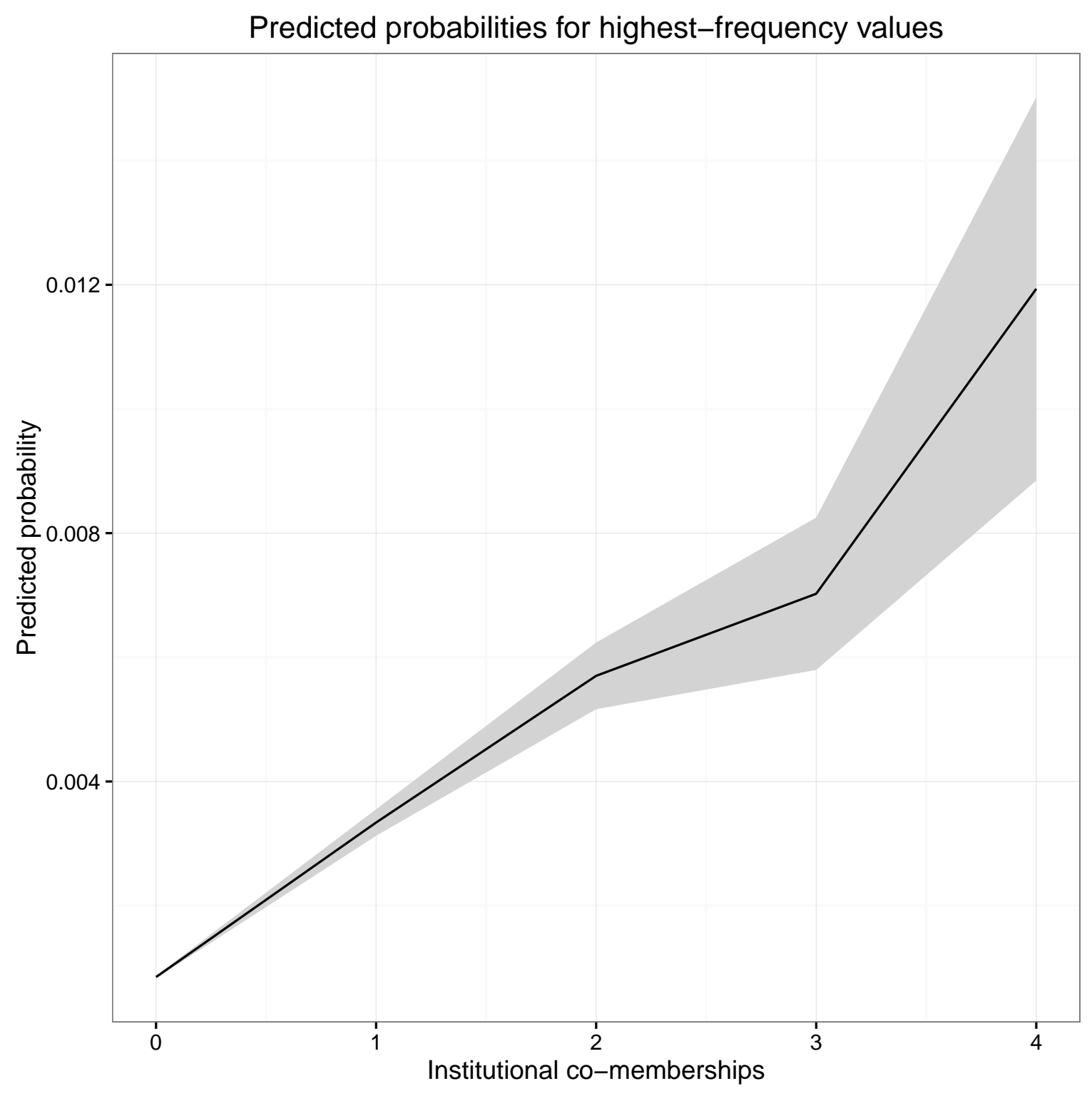

Supplementary Figure 7: Predicted probabilities for the most prevalent values on the Institutional co-memberships variable. The gray area denotes the 95 percent confidence interval around the line, which represents the mean predicted probability. 